\title{
Design and Analysis of Rectangular Microstrip Patch Antenna for ZigBee Applications
}

\author{
Sanya Srivastava \\ Research Scholar, Dept. of Electronics \& \\ Communication Engineering \\ Poornima University, Jaipur, INDIA
}

\author{
Devendra Somwanshi \\ Assistant Professor, Dept. of Electronics \& \\ Communication Engineering \\ Poornima University, Jaipur, INDIA
}

\begin{abstract}
A rectangular microstrip patch antenna is presented in this paper for $915 \mathrm{MHz}$ band applications. These applications include ZigBee and Bluetooth. The potential of ZigBee technology is enormous due to its tremendous advantages such as the capability to provide extremely fast data rates at short transmission distances while requiring very low power dissipation. Recently, printed antennas have played a major rule in development of antennas with different frequencies. The construction of proposed antenna is done on FR-4 epoxy substrate with thickness of $1.6 \mathrm{~mm}$ and $\varepsilon_{\mathrm{r}}=4.4$. The proposed antenna operates from $902 \mathrm{MHz}$ to $928 \mathrm{MHz}$ with good omnidirectional radiation patterns, its narrow band impedance bandwidth protect it from interference problem from other applications in ISM band. Proposed antenna has compact size of $(60 \times 30) \mathrm{mm}^{2}$. It has advantages in simple design, narrow bandwidth, and compact in size and easy in fabrication. The measured result is in good agreement with simulated one.
\end{abstract}

\section{Keywords}

ZigBee Antenna; ISM Band Antenna; Bluetooth Antenna; Omnidirectional Antenna.

\section{INTRODUCTION}

In recent years, many significant developments and high attention are being paid to ZigBee technology since the license free ISM frequency spectrum for commercial communications and applications. The attractive nature of ZigBee coupled with the rapid growth in wireless communication systems has made ZigBee an outstanding technology to replace the conventional and popular wireless technology in use today like Bluetooth. The concurrent surge of wireless applications, with the high level of miniaturization and higher frequency of operation, has increased the interest in designing high performance antenna types. Various type of antennas design have been presented in literature to enhance the ZigBee performance

To maximize the performance of transceiver without changing its costly architecture, advanced antenna design should be used since the antenna is an integral part of the transceiver. Also, it has played a crucial role to increase the performance and decrease the complexity of the overall transceiver.

To maturate ZigBee technology, there are many challenges that must be overcome. One fundamental challenge is to design ZigBee antennas that can satisfy the requirements of this technology. ZigBee has a significant effect on antenna design.

The hardest challenge in designing ZigBee antenna is attaining the narrow impedance bandwidth while maintaining high radiation efficiency. A return loss of greater than $10 \mathrm{~dB}$ is necessary in obtaining high radiation efficiency. It is required since ZigBee transmission is very low power (below the noise floor level) and has a high sensitivity.

In this paper, rectangular microstrip patch antenna has been proposed which operates for $902-928 \mathrm{MHz}$ band (ISM) using a rectangular patch. Radiating patch and a partial ground used to cover the $915 \mathrm{MHz}$ band (ISM- Band) from $902-928 \mathrm{MHz}$ with VSWR less than 2 . The complete antenna size is $60 \times 30$ $\mathrm{mm}^{2}$. The proposed antenna has compact size which is added advantage to use it in wireless sensor networks Mote modules.

\section{ANTENNA DESIGN AND DIMENTIONS FINALIZATION}

After an exhaustive literature review of the papers ranging from the year 1996-2014, there have been different types of approaches for making the small size antenna which are used only for ZigBee applications. For ZigBee technology there are various antennas used at $915 \mathrm{MHZ}$ frequency, like Micro strip patch antenna or PCB antenna, Chip antenna, Helical Wound Stub antenna, Low Profile Dome antenna, Dipole antenna with flying lead etc.

Nowadays, in mobile communication systems, the requirement of small sized antenna for miniaturization purpose of mobile units has been increased. Hence, reduced size and enhanced bandwidth are the major considerations in microstrip antennas for practical applications. Therefore, study regarding small size and enhanced bandwidth of microstrip antenna has been greatly increased. In the past few years, great progress in the design of small sized micro strip antenna with dual and circular polarization, dual frequency, broadband and gain enhanced performance has been reported hence we select the microstrip patch antenna for Zigbee application. There are many types of shapes which can be selected for patch. Comparison Analysis of Different types of patch shapes are listed bellow in table 1, which is created in the basis of literature review. 
Table 1. Comparison Analysis of Different types of patch shapes

\begin{tabular}{|c|c|c|c|c|c|}
\hline $\begin{array}{l}\mathrm{N} \\
\mathrm{o}\end{array}$ & $\begin{array}{l}\text { Paramete } \\
\text { rs }\end{array}$ & $\begin{array}{l}\text { Rectangul } \\
\text { ar shaped } \\
\text { patch } \\
\text { micro } \\
\text { strip } \\
\text { antenna }\end{array}$ & $\begin{array}{l}\text { Elliptical } \\
\text { shaped } \\
\text { patch } \\
\text { micro } \\
\text { strip } \\
\text { antenna }\end{array}$ & $\begin{array}{l}\text { Annular } \\
\text { ring } \\
\text { shaped } \\
\text { patch } \\
\text { micro } \\
\text { strip } \\
\text { antenna }\end{array}$ & $\begin{array}{c}\text { Tria } \\
\text { ngul } \\
\text { ar } \\
\text { patc } \\
\mathrm{h} \\
\text { mic } \\
\text { ro } \\
\text { strip } \\
\text { ante } \\
\text { nna }\end{array}$ \\
\hline 1. & $\begin{array}{c}\text { Operatin } \\
\mathrm{g} \\
\text { Frequenc } \\
\mathrm{y} \\
\mathrm{GHz}\end{array}$ & $2.43 \mathrm{GHz}$ & $\begin{array}{l}2.43 \\
\mathrm{GHz}\end{array}$ & $\begin{array}{l}2.43 \\
\mathrm{GHz}\end{array}$ & $\begin{array}{c}2.43 \\
\mathrm{GH} \\
\mathrm{z}\end{array}$ \\
\hline 2. & $\begin{array}{c}\text { Return } \\
\text { Loss dB }\end{array}$ & $\begin{array}{c}-49.2762 \\
\mathrm{~dB}\end{array}$ & $\begin{array}{c}-42.4581 \\
\mathrm{~dB}\end{array}$ & $\begin{array}{c}-30.87 \\
\mathrm{~dB}\end{array}$ & $\begin{array}{c}- \\
40.7 \\
632 \\
d B\end{array}$ \\
\hline 3. & $\begin{array}{c}\text { Impact } \\
\text { on shape } \\
\text { on } \\
\text { bandwidt } \\
\text { h MHz }\end{array}$ & $46 \mathrm{MHz}$ & $\begin{array}{l}47.6 \\
\mathrm{MHz}\end{array}$ & $\begin{array}{l}34.9 \\
\mathrm{MHz}\end{array}$ & $\begin{array}{c}42.2 \\
\mathrm{MH} \\
\mathrm{z}\end{array}$ \\
\hline 4. & $\begin{array}{c}\text { Impedan } \\
\text { ce real } \\
\text { part ohm }\end{array}$ & $\begin{array}{c}50.4380 \\
\text { ohm }\end{array}$ & $\begin{array}{c}50.0025 \\
\text { ohm }\end{array}$ & $\begin{array}{c}48.0915 \\
3 \mathrm{ohm}\end{array}$ & $\begin{array}{c}50.3 \\
042 \\
\text { ohm } \\
\end{array}$ \\
\hline 5. & $\begin{array}{l}\text { Impedan } \\
\text { ce } \\
\text { Imaginar } \\
\text { y Part } \\
\text { ohm }\end{array}$ & $\begin{array}{c}0.3360 \\
\text { ohm }\end{array}$ & $\begin{array}{c}0.4509 \\
\text { ohm }\end{array}$ & $\begin{array}{c}2.7686 \\
\text { ohm }\end{array}$ & $\begin{array}{c}0.15 \\
89 \\
\text { ohm }\end{array}$ \\
\hline 6. & $\begin{array}{c}\text { VSWR } \\
\text { dB }\end{array}$ & $1.0220 \mathrm{~dB}$ & $\begin{array}{c}1.0152 \\
\mathrm{~dB}\end{array}$ & $\begin{array}{c}1.0589 \\
\mathrm{~dB}\end{array}$ & $\begin{array}{c}1.01 \\
85 \\
\mathrm{~dB}\end{array}$ \\
\hline 7. & $\begin{array}{c}\text { Directivi } \\
\text { ty } \\
=0 \mathrm{deg}\end{array}$ & 3.8363 & 4.0114 & 0.3443 & $\begin{array}{c}3.37 \\
06\end{array}$ \\
\hline 8. & $\begin{array}{c}\text { Directivi } \\
\text { ty } \\
=90 \mathrm{deg}\end{array}$ & 3.8387 & 4.0114 & 0.3318 & $\begin{array}{c}3.36 \\
09\end{array}$ \\
\hline
\end{tabular}

Hence according to the table 1 , which is created in the basis of literature review, it is clear that rectangular patch is best for ZigBee band application in comparison to any other i.e. annular, elliptical etc. Therefore rectangular patch is to be selected. The flow chart for selecting the dimensions for antenna is as bellow.

The value which, get from the Convocational method is very large i.e. $\mathrm{L}=99$ and $\mathrm{W}=78$, so the dimensions of antenna are to be obtained by introducing external components or making some modification in dimensions of antenna. In the fig.1, the flow cart makes the whole process easy to understand.

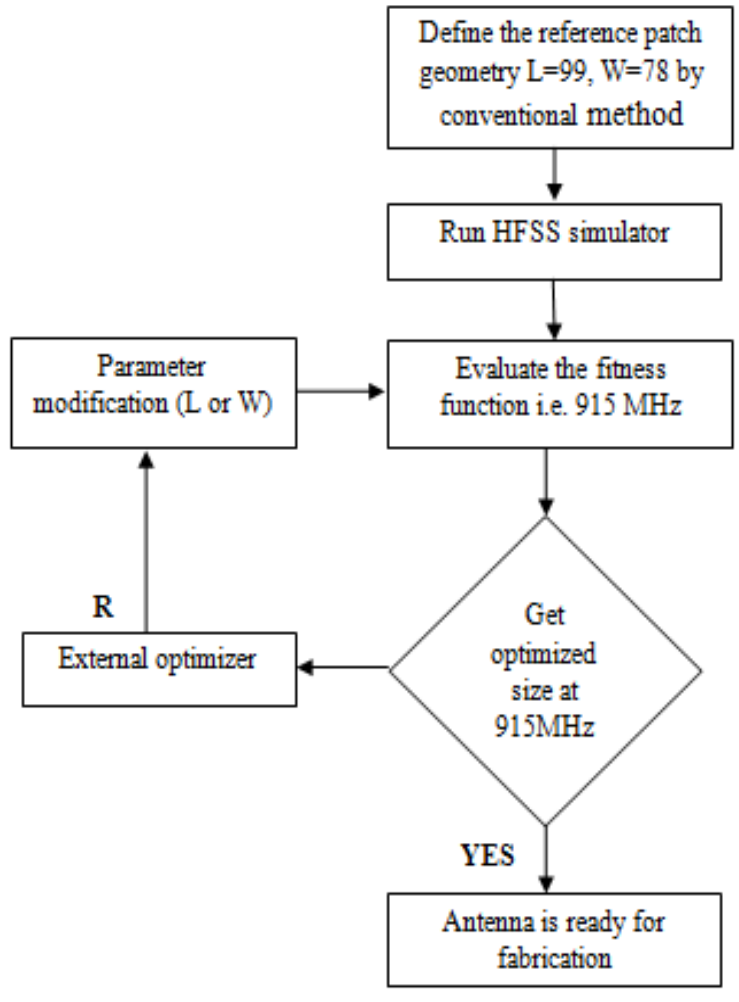

Fig. 1 Flow Chart of Antenna Dimentions Finalization

At first define the reference patch geometry i.e. the value which gets from the conventional method. After calculating the parameters, simulating software will be decided for antenna. After analyzing the antenna model with simulator, evaluate the fitness function i.e. $915 \mathrm{MHz}$ frequency. If optimized size of antenna is to be obtained at desired frequency range it means antenna is to be ready for fabrication. Otherwise some external components are to be used or make some modifications in dimensions of antenna to achieved desired output. Whole process will be followed until desired output will not be achieved. The optimized dimensions of proposed antenna have shown in table 2 .

Table 2. Optimized dimensions of proposed antenna

\begin{tabular}{|c|c|c|c|c|c|c|c|}
\hline $\begin{array}{c}\text { Paramete } \\
\mathrm{rs}\end{array}$ & $\mathrm{W}_{\mathrm{s}}$ & $\mathrm{L}_{\mathrm{s}}$ & $\mathrm{Wg}$ & $\mathrm{Lg}$ & $\mathrm{Lp}$ & $\mathrm{W}_{\mathrm{p}}$ & $\mathrm{L}_{\mathrm{f}}$ \\
\hline $\begin{array}{c}\text { Unit } \\
(\mathrm{mm})\end{array}$ & 30 & 60 & 30 & 06 & 14.8 & 20 & $\begin{array}{c}44 \\
.3\end{array}$ \\
\hline $\begin{array}{c}\text { Paramete } \\
\mathrm{rs}\end{array}$ & $\mathrm{W}_{\mathrm{f}}$ & $\mathrm{S}_{\mathrm{w} 1}$ & $\mathrm{~S}_{\mathrm{w} 2}$ & $\mathrm{~S}_{\mathrm{w} 3}$ & $\mathrm{~S}_{1}\left(\mathrm{~L}_{\mathrm{s} 1}\right)$ & $\begin{array}{c}\mathrm{S}_{2} \\
\left(\mathrm{~L}_{\mathrm{s} 2}\right)\end{array}$ & $\mathrm{S}_{3}$ \\
\hline $\begin{array}{c}\text { Unit } \\
(\mathrm{mm})\end{array}$ & 03 & 1.4 & 2 & 1 & 33 & 9.6 & $\begin{array}{c}1 . \\
6\end{array}$ \\
\hline
\end{tabular}

\section{ANTENNA DESIGN AND ANALYSIS}

To finalize the antenna design, all the geometry and configuration are done with the Ansoft HFSS 13. Fig 2 shows the top and back view of final proposed antenna. Thickness of $1.6 \mathrm{~mm}$, relative dielectric constant of $\varepsilon_{\mathrm{r}}=4.4$, and loss tangent of 0.02 . This antenna is printed on the FR-4 substrate with The proposed antenna is fed by a microstrip feeder, and the width of the microstrip feed line is $3 \mathrm{~mm}$ to achieve $50-\Omega$ characteristic impedance. There is a partial ground and UWB primary antenna Fig.1.The size of primary antenna has been chosen such that it provides a pass band of $915 \mathrm{MHz}$ band (ISM), but in simple rectangular patch it was very difficult to achieve ISM pass band, so here we have introduce open stub 
symmetry, integrated and the dimensions which we have chosen are $\mathrm{W}_{\mathrm{p}}=2 \mathrm{omm}, \mathrm{L}_{\mathrm{p}}=44.3 \mathrm{~mm}, \mathrm{~S}_{1}=3 \mathrm{~mm}, \mathrm{~S}_{2}=9.6 \mathrm{~mm}$ and $S_{3}=1.6 \mathrm{~mm}$. The partial ground is used here to control the ISM pass band i.e. $\mathrm{W}_{\mathrm{g}}=30 \mathrm{~mm}, \mathrm{~L}_{\mathrm{g}}=60 \mathrm{~mm}$.

The optimized dimension of the proposed antenna has been presented in table 2. Front and back view of proposed antenna geometry has shown in fig. 2.(a) \& (b), respectively.

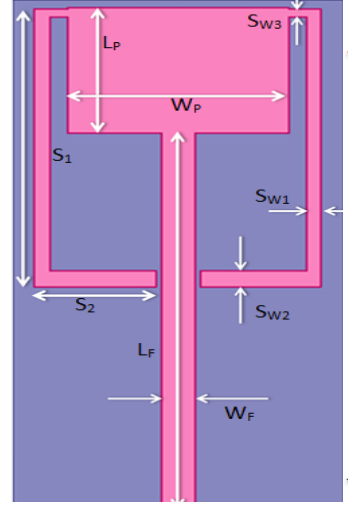

(a)

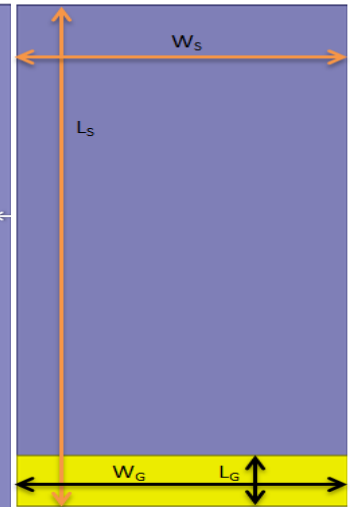

(b)
Fig.2. (a) Top view of Proposed Antenna (b) Back view of Proposed Antenna

Front and back view of fabricated proposed antenna has been presented in fig. 3.(a) \& (b), respectively as bellow.

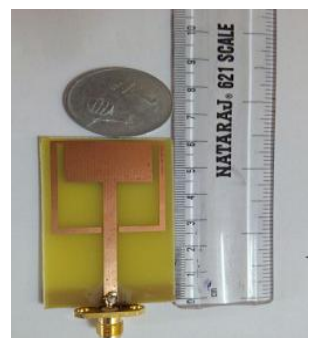

Front View



Back View

\section{Fig.3. Fabricated Proposed Antenna}

To obtain the ISM pass band characteristic from proposed antenna, first of all calculate the dimentions of basic antenna i.e. UWB primary antenna. Then integrated two open stubs symmetry with primary antenna to achived desired frequency, in fig.2 (a), which provides the passband in ISM band. The return loss $\left(\mathrm{S}_{11}\right.$ in $\left.\mathrm{dB}\right)$ after integrating two open stubs symmetry is presented in fig.4. From fig. 4 , it is seen that proposed antenna provides a single passband characteristic in ISM band. from fig. 4, it is seen that proposed antenna is able to operate on Zigbee Band at desired frequency $915 \mathrm{MHz}$. Simulation of proposed antenna is to be done with HFSS simulator.

HFSS is based on FEM method, so it can say that the frequency domain analysis of proposed antenna shows desired output.

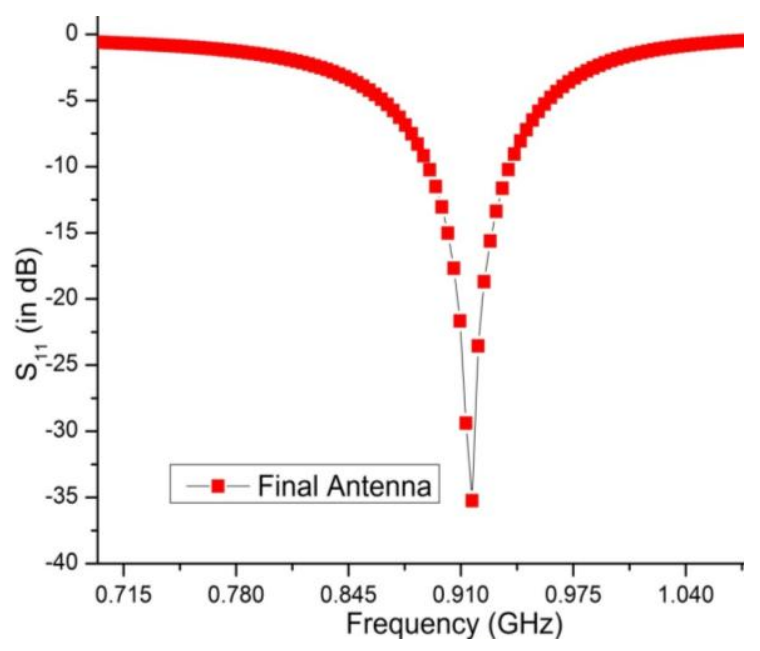

Fig. 4 .Return loss vs. Frequency graph

Length of ground namely $\mathrm{L}_{\mathrm{g}}$ varied with a range of values and results are presented.

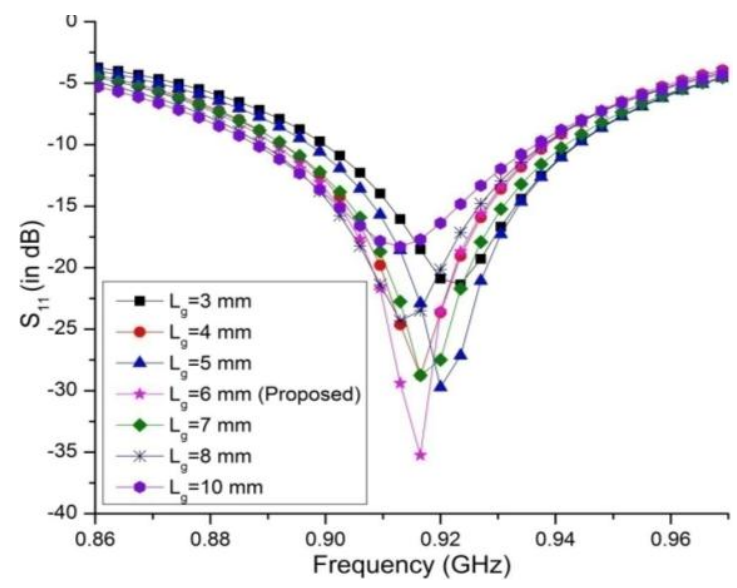

Fig. 5. $S_{11}$ in (dB) vs Frequency graph for variation in length of graund

From fig.5, it is seen that with the length of ground $\mathrm{L}_{\mathrm{g}}$ at 3 $\mathrm{mm}, 4 \mathrm{~mm}$ and $5 \mathrm{~mm}$, our desired ISM band can not be achieved but with $6 \mathrm{~mm}$, desired band is achieved. The width optimization of Sutbs $S_{\mathrm{w} 1}$ and its effect on the $S_{11}$ has been shown in fig. 6. Proposed width $S_{\mathrm{w} 1}$ is $1.4 \mathrm{~mm}$.



Fig. 6. $S_{11}$ (in dB) Vs Frequency graph for variation in Width of stub $S_{1}$ 
Stubs ' $\mathrm{S}_{2}$ ' which is integrated with primary antenna, varied with a range of values and results are presented.

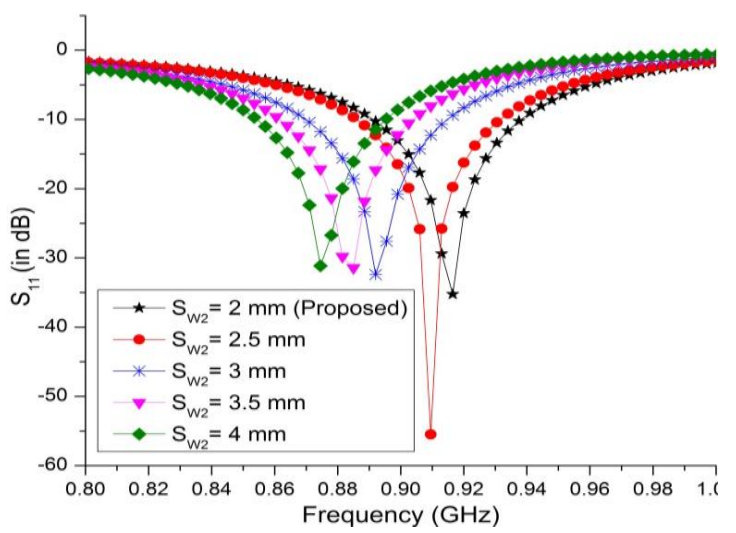

Fig.7. $S_{11}$ (in dB) Vs Frequency graph for variation in Width of stub $S_{2}$

From fig.7, it is clear that with the width of $S_{2}$ at $2.5 \mathrm{~mm}, 3.0$ $\mathrm{mm}, 3.5 \mathrm{~mm}$ and $4.0 \mathrm{~mm}$, our desired ISM band can not be achieved but with $2.0 \mathrm{~mm}$, desired band is achieved. The stubs $S_{2}$ width optimization and its effect on the $S_{11}$ has been shown in fig. 7. Proposed width of stub $S_{2}$ is $2.0 \mathrm{~mm}$.

In order to observe the effect of open stubs on current distribution, from fig. 8 it is seen that due to the stub current density is highly disturbed so there is a resonance at $915 \mathrm{MHz}$ frequency. It is clear from the Fig. 8 that the accumulation of current density near the edges of the slot is very strong that shows a positive sign to create the resonance at ZigBee band.



Fig. 8. Vector current distribution due the stub $S_{1}$ at 915 $\mathrm{MHz}$

\section{RESULT AND DISCUSSION}

The fabricated antenna was tested and by using vector network analyzer for calibration the return loss variation graph for simulated and fabricated antenna is to be obtained which has shown in Fig.9. Measured result shows good agreement with the simulated result. The antenna with ISM band $(915 \mathrm{MHz})$, maintaining the required bandwidth (902$928 \mathrm{MHz}$ ) with VSWR less than 2. The simulated radiation pattern at $915 \mathrm{MHz}$ has been shown in Fig.10. At the 915 $\mathrm{MHz}$ frequency 3-D polar plot of gain is presented in Fig.11. From Fig. 11 it is seen that the gain is $\mathrm{dB}$, as it is known that the ISM band applications required a very low power rating so achieved gain is sufficient to fulfill the required gain in this band. The proposed antenna is able to display good omnidirectional radiation patterns in the $\mathrm{H}$-plane and dipole like radiation patterns in E- plane as shown in Fig.10.

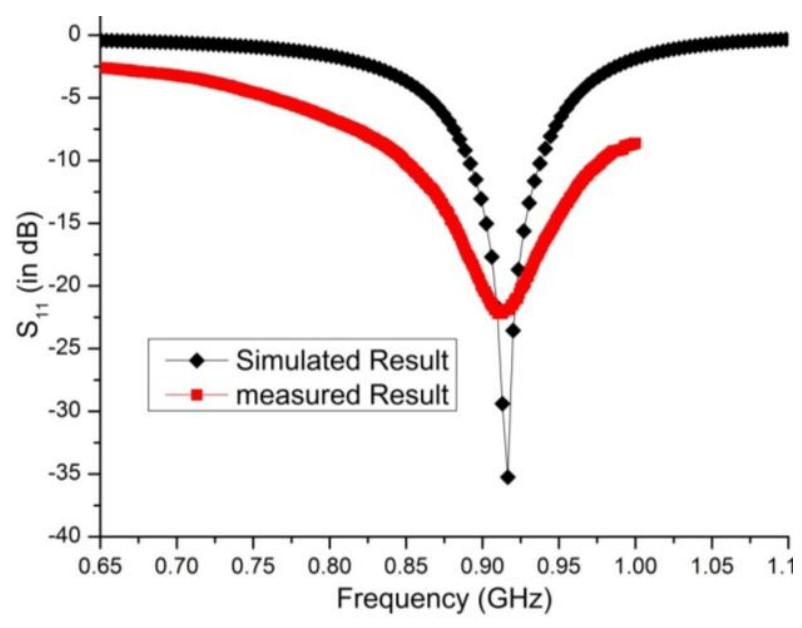

Fig. 9. $S_{11}$ Vs frequency

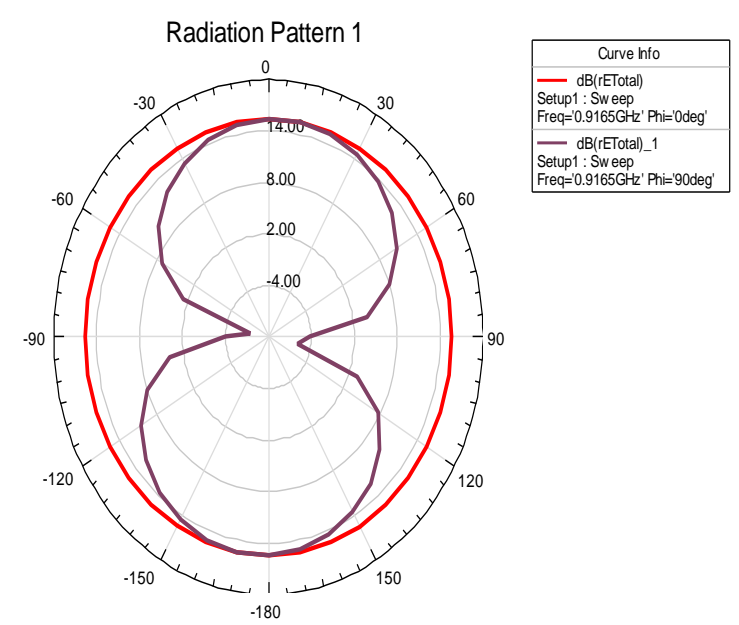

Fig. 10. Radiation patter at $915 \mathrm{MHz}$ of proposed antenna.
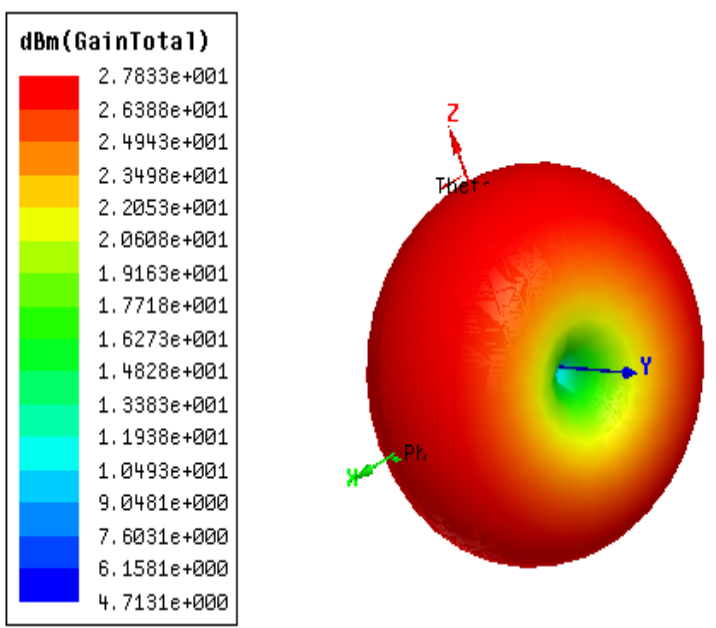

Fig. 11. 3-D Polar plot of gain at 915MHz of proposed antenna.

\section{CONCLUSION}

A compact ZigBee antenna is presented in this paper. This antenna has simple structure and compact size of $(60 \times 30)$ $\mathrm{mm}^{2}$. This is easy to be integrated in miniature devices. Proposed antenna covers frequency band from 902-928 MHz, where simulated and measured results are good in agreement. The performance parameters while simulated are return loss - 
$35 \mathrm{dBi}$, gain $2.73 \mathrm{dBm}$ and directivity $2.83 \mathrm{dBm}$ and while it is tested are return loss $-30 \mathrm{dBi}$, gain $2.46 \mathrm{dBm}$ and directivity is $2.52 \mathrm{dBm}$. Results \& analysis of this antenna indicates that it is applicable in miniature devices, simple design \& compact size as added advantage, which can easily be used in embedded wireless system applications. Surface current distributions were used to show the effect of these slots in getting the ISM band.

\section{ACKNOWLEDGMENT}

Authors are thankful to Mr. Krishna Ranshu Ranjan, Assistant Professor, G.B. Pant Engineering College, and New Delhi, INDIA for providing the measuring facilities and useful discussions.

\section{REFERENCES}

[1] Z. D. Liu andP . S. Hall, "Dual-band antenna for handheld portabletelephones," Electron. Lett., vol. 32, pp. 609-610, 1996.

[2] P. Salonen, M. Keskilammi, andM. Kivikoski, "New slot configurationsfor dual-band planar inverted-F antenna," Microwave Opt. Technol.Lett., vol. 28, pp. 293-298, 2001.

[3] H. C. Tung andK. L. Wong, "A shorted microstrip antenna for $2.4 / 5.2 \mathrm{GHz}$ dual-band operation," Microwave Opt. Technol. Lett., vol. 30, pp.401-402, 2001.

[4] M. J. Ammann and L. E. Doyle, "A loaded inverted-F antenna for mobilehandset," Microwave Opt. Technol. Lett., vol. 28, pp. 226-228, 2001.

[5] Y. H. Suh andK. Chang, "Low cost microstrip-fed dual frequencyprinteddipole antenna for wireless communications," Electron. Lett.vol. 36, pp. 1177-1179, 2000 .
[6] M. Ali andG. J. Hayes, "Analysis of integrated invertedF antennas forBluetooth application," in Proc. IEEE-APS Conf. Antennas and Propagationfor Wireless Communications, Waltham, MA, 2000, pp. 21-24.

[7] J. Y. Jan andL. C. Tseng, "Planar monopole antennas for 2.4/5.2 GHzdual-band application," in Proc. IEEE-APS Int. Symp. Dig., Columbus,OH, 2003, pp. 158-161.

[8] F. Shahin, "ZigBee Wireless Networks and Transceivers", 2008.

[9] Fred Eady, "Hands-On ZigBee: Implementing 802.15.4 with Microcontrollers",2007.

[10] Diane MCMichael Glister, "Bluetooth End to End", Wiley, 2002.

[11] C. A. Balanis, "Antenna Theory Analysis and Design", 2nd Edition,John Wiley \& Sons, 1997.

[12] J. D. Kraus, and Marhefka, R. J., "Antennas for All Applications", $3{ }^{\text {rd }}$ Edition, PHI. 2002.

[13] Yen-Liang Kuo, Kin-Lu Wong, "Printed Double-T Monopole Antennafor 2.4/5.2 GHz Dual-Band WLAN Operation" IEEE transaction onantennas and propagation, vol.51, no. 9, September 2003.

[14] Jen-Yea Jan, Liang-Chi Tseng, "Small Planar Monopole Antenna witha Shorted Parasitic Inverted-L Wire for Wireless Communications inthe 2.4-, 5.2-, and 5.8-GHz Bands" IEEE transaction on antennas and propagation, vol. 52, no. 7, July 2004 .

[15] P. C. Bybi, Gijo Augustin, B. Jitha, C. K. Aanandan, K. Vasudevan,P. Mohanan, "A Quasi-Omnidirectional Antenna for Modern wirelessCommunication Gadgets" IEEE transaction on antennas and propagation letters, vol. 7, 2008. 